\title{
Sub-pixel Area Calculation Methods for Estimating Irrigated Areas
}

\author{
Prasad S. Thenkabail ${ }^{1, *}$, Chandrashekhar M. Biradar ${ }^{2}$, Praveen Noojipady ${ }^{3}$, Xueliang Cai $^{1}$, \\ Venkateswarlu Dheeravath ${ }^{1}$, Yuanjie Li $^{3}$, Manohar Velpuri ${ }^{4}$, MuraliKrishna Gumma ${ }^{1}$ \\ and Suraj Pandey ${ }^{1}$
}

1 International Water Management Institute, Colombo, Sri Lanka.

2 Institute for the Study of Earth, Oceans and Space (EOS), University of New Hampshire, USA

3 Department of Geography, University of Maryland, USA

4 Geographic Information Science Center of Excellence, South Dakota State University, USA

* Author to whom correspondence should be addressed. E-mail: p.thenkabail@cgiar.org

Received: 1 October 2007 / Accepted: 21 October 2007 / Published: 31 October 2007

\begin{abstract}
The goal of this paper was to develop and demonstrate practical methods for computing sub-pixel areas (SPAs) from coarse-resolution satellite sensor data. The methods were tested and verified using: (a) global irrigated area map (GIAM) at 10-km resolution based, primarily, on AVHRR data, and (b) irrigated area map for India at 500-m based, primarily, on MODIS data. The sub-pixel irrigated areas (SPIAs) from coarseresolution satellite sensor data were estimated by multiplying the full pixel irrigated areas (FPIAs) with irrigated area fractions (IAFs). Three methods were presented for IAF computation: (a) Google Earth Estimate (IAF-GEE); (b) High resolution imagery (IAFHRI); and (c) Sub-pixel de-composition technique (IAF-SPDT). The IAF-GEE involved the use of "zoom-in-views" of sub-meter to 4-meter very high resolution imagery (VHRI) from Google Earth and helped determine total area available for irrigation (TAAI) or net irrigated areas that does not consider intensity or seasonality of irrigation. The IAF-HRI is a well known method that uses finer-resolution data to determine SPAs of the coarserresolution imagery. The IAF-SPDT is a unique and innovative method wherein SPAs are determined based on the precise location of every pixel of a class in 2-dimensional brightness-greenness-wetness (BGW) feature-space plot of red band versus near-infrared band spectral reflectivity. The SPIAs computed using IAF-SPDT for the GIAM was within $2 \%$ of the SPIA computed using well known IAF-HRI. Further the fractions from the 2
\end{abstract}


methods were significantly correlated. The IAF-HRI and IAF-SPDT help to determine annualized or gross irrigated areas (AIA) that does consider intensity or seasonality (e.g., sum of areas from season 1, season 2, and continuous year-round crops). The national census based irrigated areas for the top 40 irrigated nations (which covers about $90 \%$ of global irrigation) was significantly better related (and had lesser uncertainties and errors) when compared to SPIAs than FPIAs derived using $10-\mathrm{km}$ and $500-\mathrm{m}$ data. The SPIAs were closer to actual areas whereas FPIAs grossly over-estimate areas. The research clearly demonstrated the value and the importance of sub-pixel areas as opposed to full pixel areas and presented 3 innovative methods for computing the same.

Keywords: sub-pixel areas; sub-pixel de-composition technique; high-resolution imagery; irrigated area fractions, IAF-SPDT; IAF-HRI; IAF-GEE

\section{Introduction}

Pixel size plays an important role in area computations, especially when coarser-resolution data are used. For example, a single Advanced Very High Resolution Radiometer (AVHRR) 10-kilometer pixel constitutes a full pixel area (FPA) of 10,000 hectares and Moderate Resolution Imaging Spectroradiometer (MODIS) 500-meter constitutes an FPA of 25 hectares. So, in many cases, only a fraction of a coarse resolution pixel falls under a particular land cover. The sub-pixel areas (SPAs) represent actual areas. The SPAs are computed by multiplying FPAs with irrigated area fraction (IAF). A comparative study for china [1] in estimating the areas derived from AVHRR Version 2.0 International Geosphere-Biospere Programme (IGBP) DIScover [2] dataset showed that about half of the DIScover cropland pixels had less than $60 \%$ fractional cropland cover within a pixel size of 1-km. The pixel was named "irrigated" because it has certain percentage of area within the pixel which is irrigated- which can, typically, vary from a nominal $10 \%$ to $100 \%$. It is, thereby, obvious that counting whole pixels can lead to over estimation of actual areas [3]. In the AVHRR 10-km, this issue becomes even more critical since every pixel encompasses 10,000 hectares. The implication of using FPAs in place where SPAs need to be reported is of significant importance in many applications such as water use calculations, food production estimates, and global scenario modeling.

Nevertheless, the coarser resolution imagery still remains the only practical data for global or regional studies. However, they invariably result in significant errors as a result of mixed land cover composition [4]. A number of methods have been used for un-mixing the sub-pixel in the coarser resolution imagery. These methods include [5]: (a) artificial neural network (ANN), (b) mixture modeling, and (c) fuzzy c-means classification. Even though ANN is the most accurate method; accurate co-registration and the availability of a training data set are real problem [5]. The other methods of sub-pixel area estimations include [6-9]: (a) regression based approaches, (b) high resolution imagery (HRI) use, and (c) groundtruth fractions. Fang et. al. (1998) estimated rice areas from AVHRR data by using higher resolution Landsat data by linking them through a linear statistical model [10]. Comparing the cropland area [11] on a smaller landscape-scale study using SPOT VGT and Landsat TM showed an increase in the Landsat TM computed area due to the type of the landscape. Gallego et. al. (1993) and Gonzalez et. al. (1997) used high-resolution satellite images to 
evaluate crop areas through regression estimator in an area frame survey [6,7]. DeFries et. al. (1996) derived percent forest cover in each of the AVHRR 8-kilometer grid cell by two different methods over central Africa and found that the percent cover estimated by classified MSS scenes were more accurate than the multiple linear regression and regression method [12]. Quarmby et. al. (1992) used linear mixture modeling for estimating crop area for a region of $2500 \mathrm{~km}^{2}$ using multi-temporal AVHRR and recommends testing this technique to estimate crop area at national or continental scale [13]. All these studies prove that the sub-pixel fraction is essential in estimating the percentage area of a particular land cover and land use.

There are two, contrasting, inferences on the relationship between area and resolution. This is, mainly, as a result of whether the areas are calculated using SPAs or FPAs. This is discussed below taking irrigated cropland areas as an example. First, Ozdogan and Woodcock (2006) imply that finer the resolution of the imagery lesser is the cultivated area [14]. This is because, at finer resolution one can separate non-agricultural areas such as roads, settlements, barren areas, and fallow areas from cultivated agricultural areas. These areas can be significant and often as high as 30 to $40 \%$. In coarser resolution, the pixel will be considered irrigated when they are dominated by and lor significantly occupied by irrigated areas; but not necessarily entirely occupied by irrigated areas. So, in reality coarse resolution irrigated pixels, many times, consists of irrigated cropland areas as well as noncropland areas (e.g., roads, permanent fallows, settlements), leading to over-estimation of irrigated cropland areas if we consider the entire FPA as the actual area. This will lead to over-estimation of irrigated areas.

Second, finer the spatial resolution of the imagery greater is the area [8] because at finer resolution one can capture all or most of the fragmented and scattered cultivated areas where as at coarserresolution there is a good likelihood that one may miss fragmented irrigated areas completely unless the fragments within the pixels are highly significant and the irrigated cropland area fractions are determined accurately through sub-pixel de-composition. In this scenario, the coarse resolution FPA will not map fragmented cropland areas as croplands, thus under-estimating the cropland areas.

Based on the above two contrasting scenarios, the need for further investigation on the relationship between the areas and the resolutions are quite obvious. This will require building more reliable, robust, and practical methods of determining area fractions (AFs) that will lead to determining accurate areas or sub-pixel areas (SPAs).

Given the above discussions, the overarching goal of this paper was to develop methods for establishing IAFs that will lead to determining SPAs. In order to practically illustrate the methodology development, we took the global irrigated area map (GIAM; http://www.iwmigiam.org). Three distinct and unique methods of irrigated area fractions (IAFs) are discussed and illustrated. The sub-pixel irrigated areas (SPIAs) are then calculated by multiplying the full pixel irrigated areas (FPIAs) with IAFs. The study will compare the FPIA and SPIA computed from the GIAM map with actual irrigated areas obtained from the National systems.

\section{Methods}

The sub-pixel irrigated area (SPIA) computation methodology was illustrated using global irrigated area map at 10-km resolution (GIAM 10-km; Figure 1) and an irrigated area map for India derived from MODIS 500-m resolution. 


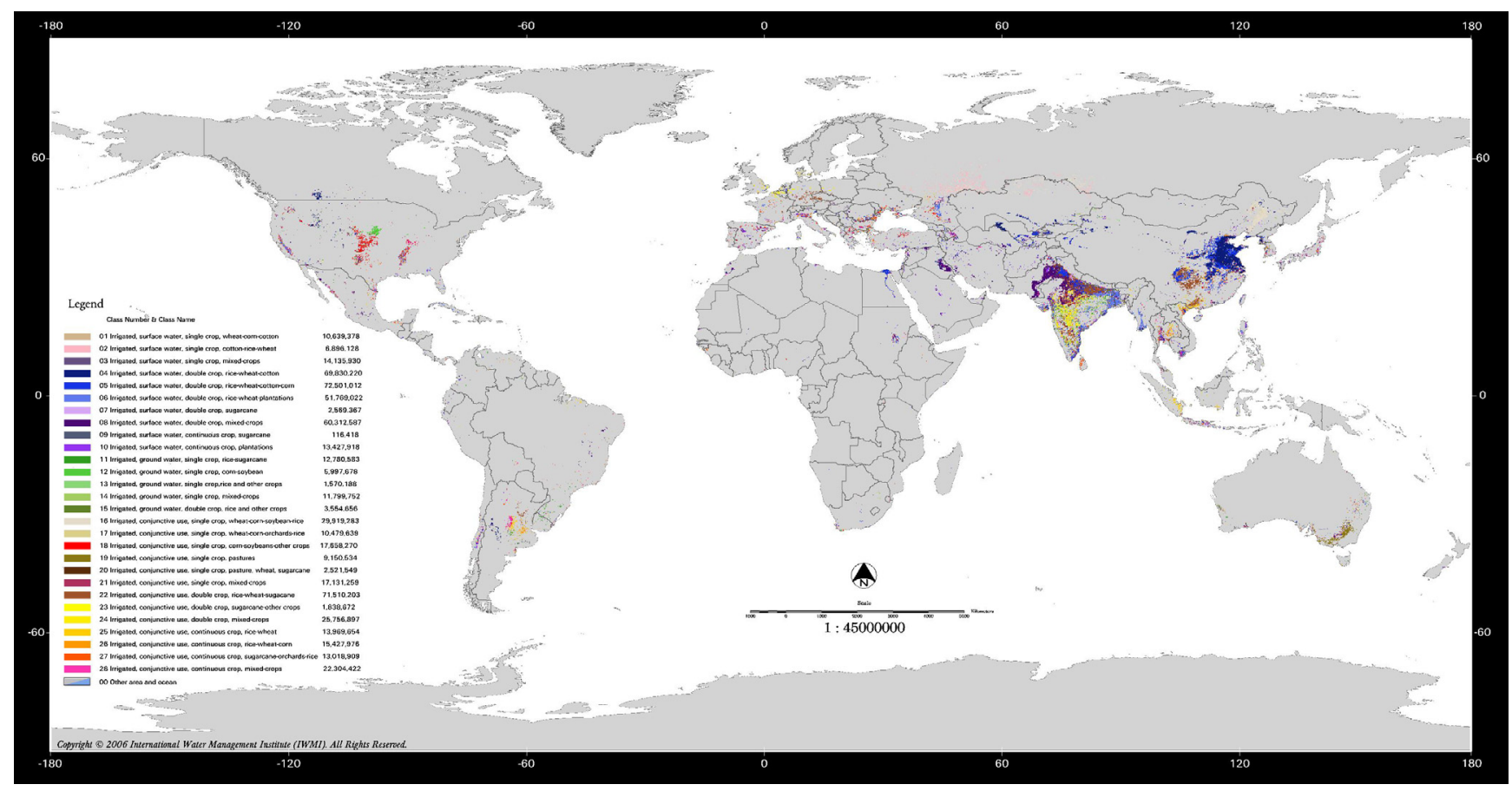

Figure 1. Full pixel irrigated areas (FPIAs) for the 28-class Global irrigated area map (GIAM28).

First, the GIAM which was produced using nominal $10-\mathrm{km}$ resolution remote sensing data in conjunction with a number of other secondary data (Figure 1, http://www.iwmigiam.org; 8) was used to compute SPIAs and compare it with areas determined using the national statistics:

$$
S P I A=F P I A * I A F
$$

Where, IAF is irrigated area fraction and FPIA is full pixel irrigated area. The FPIA's are computed directly from the digital images using any commonly used remote sensing and lor geographic information systems (GIS) software packages.

Second, MODIS 500-m data was used to determine SPIAs and compare them with national statistics.

The IAF's were determined using 3 methods as discussed below:

- Google earth estimate (IAF-GEE);

- High resolution imagery (IAF-HRI); and

- $\quad$ Sub-pixel de-composition technique (IAF-SPDT).

The methods for determining the IAFs remain the same for various resolutions; illustrated, mostly, for only $10-\mathrm{km}$ resolution below.

\subsection{IAF-GEE}

Google Earth (http://earth.google.com/) provides a large volume of sub-meter to 4 meter, very high resolution (VHR), imagery. In addition, the ability to instantly "zoom into" any spot on earth is an attractive feature for "viewing" landscape and its details in fine resolution. When zoom into a particular class (Figure 2a; already labeled as irrigated in GIAM map as shown in Figure 1) in Google 
Earth VHR imagery, the fraction of area actually irrigated can be determined (Figure 2b). IAF-GEE is defined as the irrigated area fraction (IAF) of areas that are irrigated at any given point of time plus areas that are left follow but are "equipped" for irrigation at the same point of time.

The irrigated area fractions using Google Earth Estimates (IAF-GEE) were determined for each of the 28 classes (Figure 1). The procedure involved distributing 30 to 50 well distributed random points (4 points illustrated in Figure 2a) for every class and "zooming into" these points (Figure 2a) in Google Earth to determine the IAF-GEE (Figure $2 b$ ) for each point. It is important to take note that the area has already been labeled irrigated in GIAM [8] and hence the entire area was considered irrigated in FPIA. However, the actual area irrigated was represented by SPIAs. Since the resolution of GIAM was 10-kilometers, the interpretation window in Google Earth was also fixed to $10-\mathrm{km}$ by $10-\mathrm{km}$ (Figure 2a). Within the interpretation window of $10-\mathrm{km}$ by $10-\mathrm{km}$, the percentage area irrigated was estimated by visual interpretation (Figure 2a). Once we have the IAF-GEE for every point, they are averaged to get one IAF-GEE for the class (illustrated taking 4 points in Figure 2b). Adequate numbers were selected to represent the class area and distribution in different parts of the world. Larger the size of the class, greater was the number of points. Also, when class was distributed in different parts of the world, as far as possible, points were selected to represent various locations in the world. The same approach is then repeated for all 28 classes (Figure 1b) leading to IAF-GEE values for these classes (Table 1). When we randomly zoom into points for a class where sub-meter to 4-meter data is absent in Google Earth, we select alternative points.

\subsection{IAF-HRI}

Irrigated area fraction from high resolution imagery (IAF-HRI) was computed using Landsat ETM+ imagery. The process involved (Figure 3a, 3b, and 3c):

A. Randomly selecting 3-6 locations in a GIAM28 class (e.g., illustrated for 1 location in Figure 3a);

B. Overlaying Landsat ETM +6 band-non-thermal band imagery on GIAM class area and masking out ETM+ imagery area that was outside the GIAM class area (Figure 3a);

C. Classify the masked out Landsat ETM+ imagery. Use class identification process [8, 15-16] to label classes as (Figure 3a): (i) irrigated, (ii) fallow (area equipped for irrigation, but not irrigated); and (iii) non-irrigation;

D. Determine IAF-HRI for the image;

E. Repeat the above steps for another season (Figure 3b) using seasonality determined by NDVI time-series plot (Figure 3c);

F. Repeat the above steps by taking additional Landsat ETM+ images from different portions of the image as well as from different seasons;

G. Establish IAF-HRI for each season, by averaging from several images. The resultant fractional irrigated areas shown in Table 1.

This method was earlier illustrated for establishing sub-pixel areas of forest canopies mapped using AVHRR 8-km by DeFries et. al., (1996) using Landsat MSS [12]. 

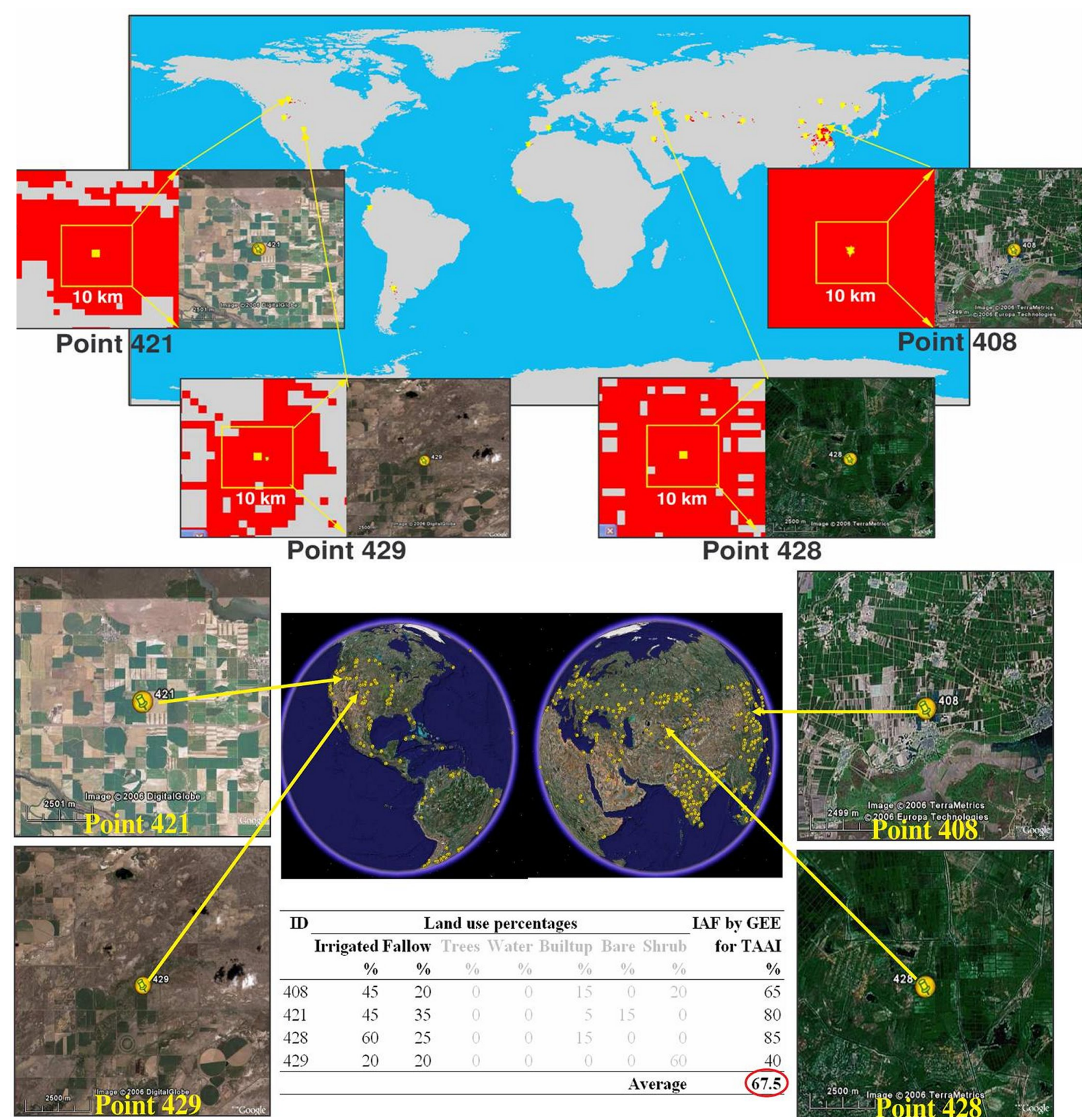

Point 429
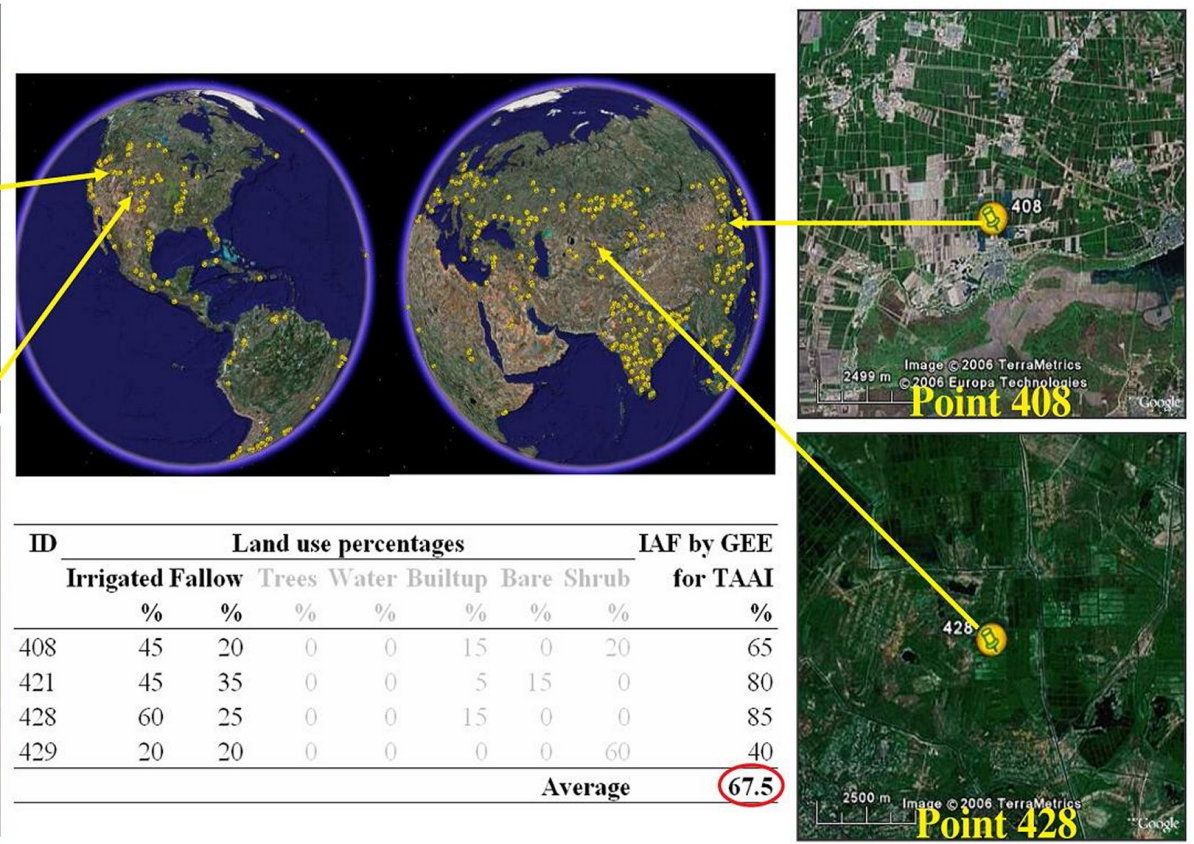

Figure 2. Irrigated area fraction from Google Earth estimated (IAF-GEE) very high resolution imagery. The "zoom in views" of a class (Figure 2a) is used to determine land cover percentages of a irrigated class from different points, which are later averaged (Figure $2 b$ ). 


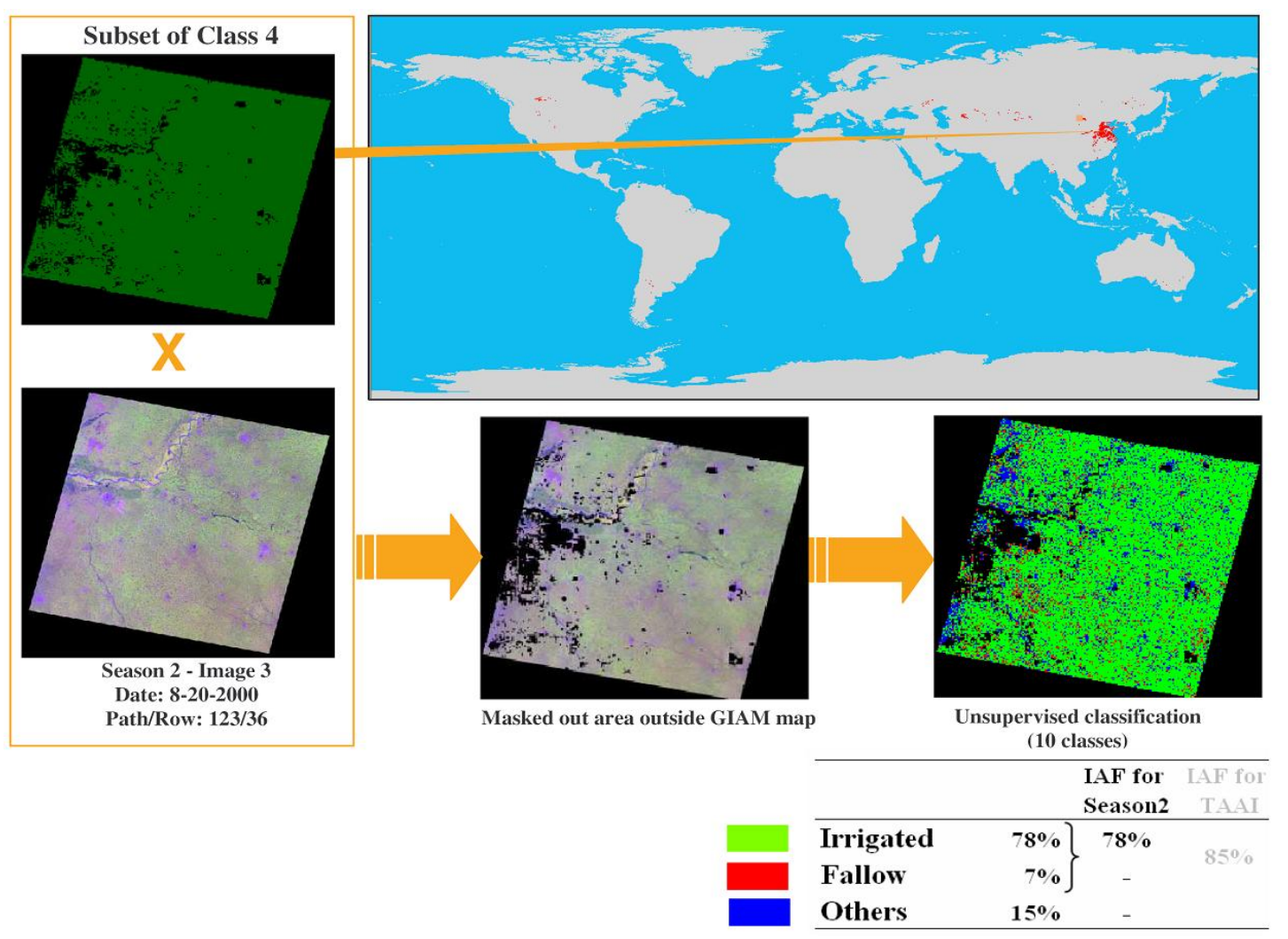

Figure 3a)
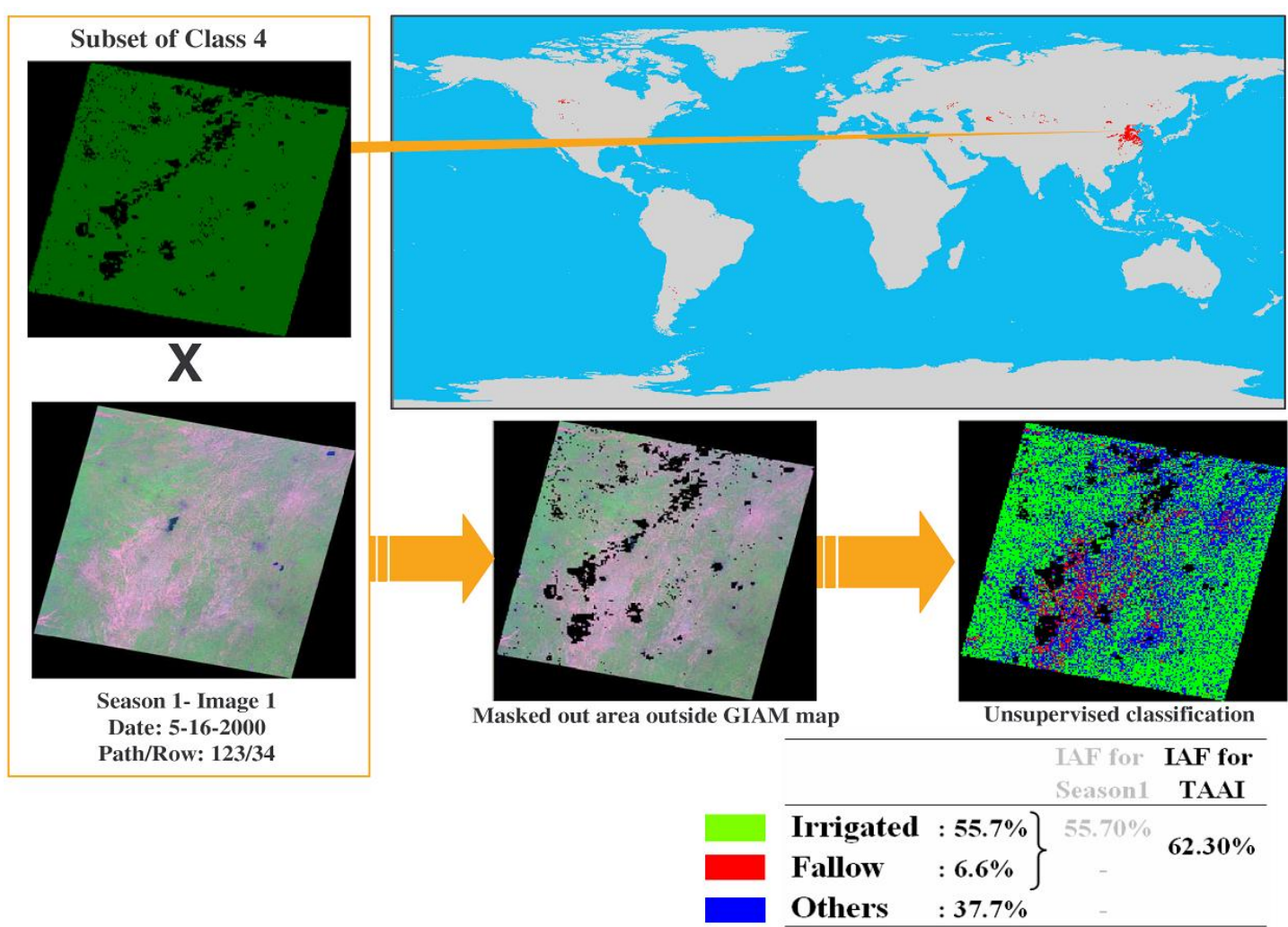

Figure $3 b$ ) 


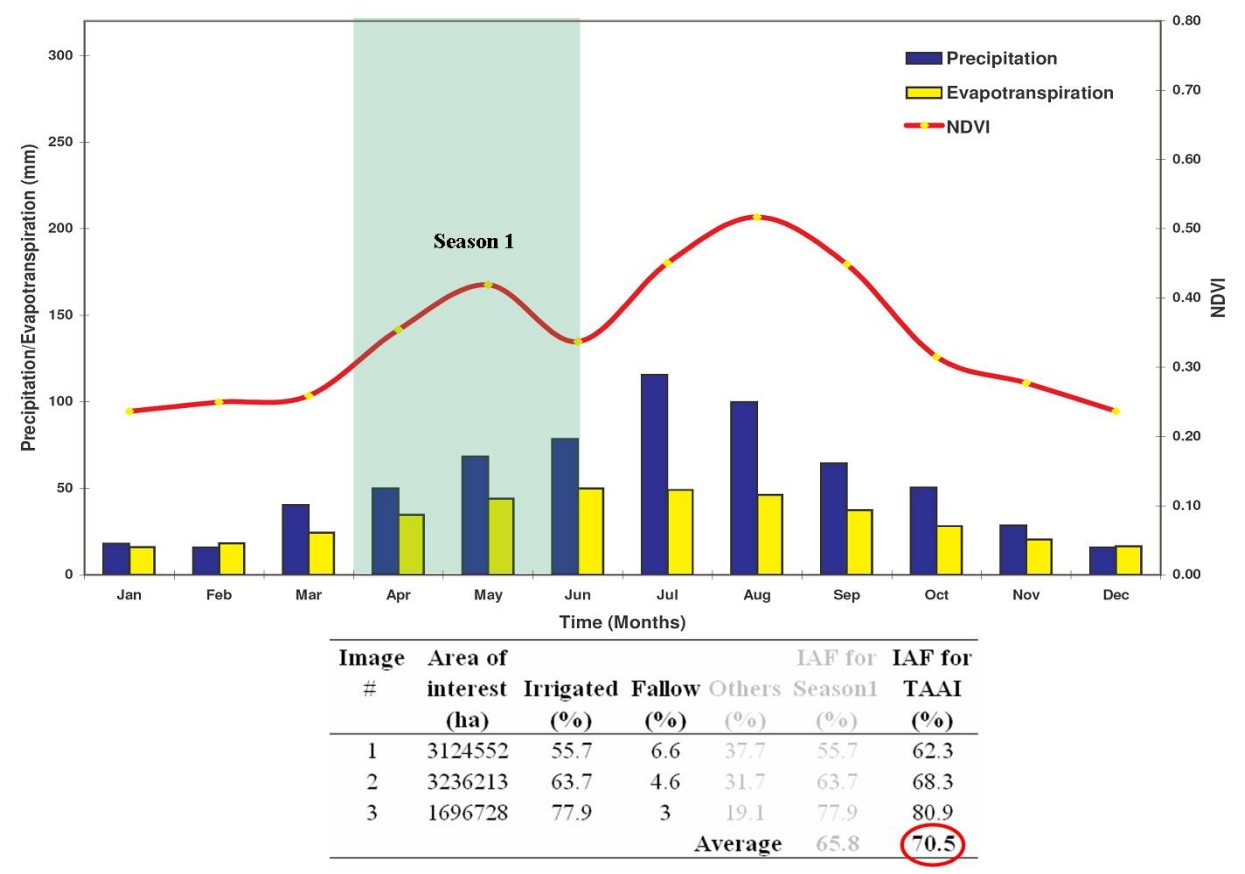

Figure 3c)

Figure 3. Irrigated area fraction from high resolution imagery (IAF-HRI). The process of IAF-HRI determination using Landsat 30m data taking images of season 1 (Figure 3b) and season 2 (Figure 3c); taking images that coincide with peak vegetation growing dates of the season (Figure $3 \mathrm{c}$ ).

\subsection{IAF-SPDT}

The irrigated area fraction using sub-pixel de-composition technique (IAF-SPDT) was based on the RED-band versus near-infrared (NIR-band) reflectivity of the pixels in a class and their location in the brightness-greenness-wetness (BGW) plots (Figure 4). The figure 4 shows the spectral reflectivity of every pixel of class 4 of the GIAM 28 class map for the season 1 (June-September) by plotting AVHRR band $1_{\min }$ (absorption maxima) versus AVHRR band $2_{\max }$ (reflection maxima). Through this effort, every pixel in the class was assigned a particular IAF percentage (Figure 4) based on where it occurs in the BGW plot. The general rule is that the IAF percentages are highest in greenness zone, lower in brightness and wetness zones, and lowest near soil lines. But, there are significant exceptions to it that needs to be noted. One such example was the flooded rice pady, the significantly lower reflectivity in AVHRR band 1 and band 2 as a result of background water even though 100\% pixel area was irrigated. The pixels will then cluster in an area between wetness and greenness zones. When assigning percentage area irrigated, we will retain $100 \%$ for this intermediate zone as well as the peak greenness zone in SPDT; since both have $100 \%$ area irrigated even when reflectivity differ significantly. The exact irrigated area percentages of pixels were determined based on observing the composition of pixels falling on different portions of SPDT in:

A. groundtruth data and digital photos,

B. high-resolution images,

C. extensive literature review showing relationships between spectral indices and percent cover [17-23], and

D. relative positioning of the RED and NIR reflectivity of pixels of a class in 2-dimensional feature space (2-d FS) SPDT [8,15]. 
Greater the understanding one has between the percent irrigated area versus band reflectivity, greater the reliability in assigning IAF percentages and the associated sub-pixel areas calculations.

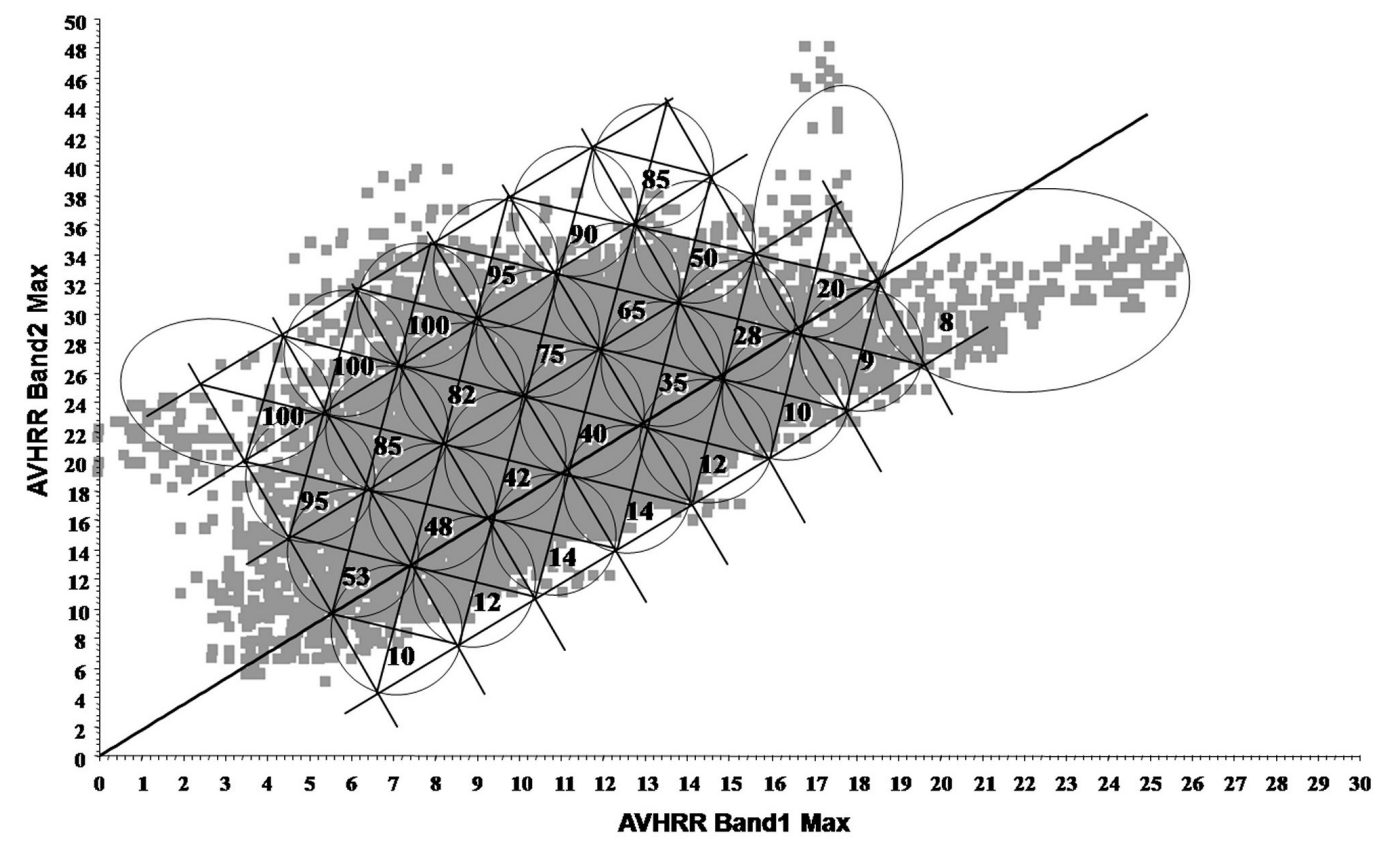

Figure 4. Irrigated area fraction from sub-pixel de-composition technique (IAF-SPDT). The red versus near-infrared reflectivity of every class of a pixel is plotted in a 2-dimensional SPDT plot. Depending on where the pixel falls in SPDT plot and IAF is determined.

\section{SPIAs}

Two types of sub-pixel irrigated areas (SPIAs, equation 1) were computed:

\subsection{Total area available for irrigation (TAAI)}

The TAAI does not consider the intensity of irrigation. The TAAI is defined as the area irrigated at any given point of time and the area left fallow at the same point of time.

\subsection{Annualized irrigated area (AIA)}

The AIA considers the intensity of irrigation. The AIA is defined as the area irrigated during different seasons: season $1+$ season $2+$ continuous year-round irrigated crops.

For each of the GIAM 28 classes, the seasonality or intensity of (e.g., single crop, double crop, and year-round crop) irrigation was established by plotting the NDVI time-series (Figure 5) which was a proxy for crop calendar and crop growth dynamics.

\section{Results and Discussion}

The irrigated area fractions (IAFs; Table 1) from the 3 methods were determined for each of the 28 GIAM classes. The IAF-HRI and IAF-SPDT were determined for season 1, season 2, and continuous year round crops (Table 1 and 2). 


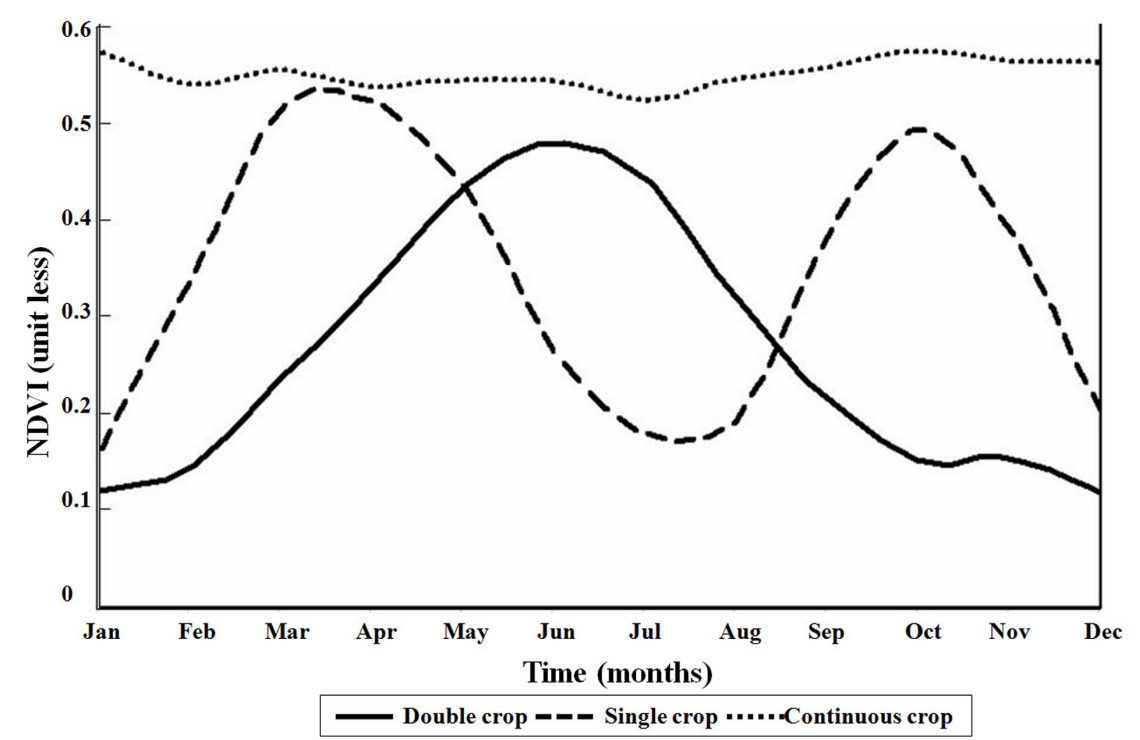

Figure 5. Intensity of irrigation and areas. Irrigated areas determined considering intensity (single crop, double crop, continuous crop in a season). Also, see Table 1 and 2.

The sub-pixel irrigated areas (SPIAs) for the GIAM 28-classes (Figure 1) were computed (Table 3) by multiplying full pixel irrigated areas (FPIAs) with irrigated area fractions (IAFs) (Table 1). The total area available for irrigation (TAAI), or the net irrigated area, was determined by taking IAF-GEE of each class and multiplying it with FPIAs of the classes. The annualized irrigated areas (AIAs), or the gross area, was determined by taking the average of the IAF-HRI and IAF-SPDT of each class and multiplying them with FPIAs of the classes for season 1, season 2, and year-round continuous crops (see crop calendar of classes in Table 2) and summing their areas (Table 3).

The SPIA and FPIA of the TAAI are represented in the Table 3. The FPIAs of the world was 589 million hectares or Mha (rounded off to nearest million) when compared with the SPIAs of 399 Mha, a difference of 190 Mha (Table 3). The SPIA of the AIAs was 480 Mha (Table 3). The AIAs considered cropping intensity (Table 2) and was calculated by multiplying FPIA with average IAF-HRI and IAFSPDT. The fractions estimated by two independent methods (Figure 6) were essential in developing confidence in IAFs and in refining them when one sees significant difference between two methods for any class.

The validity of these remote sensing based numbers were compared with the reported irrigated areas from the national statistics synthesized by the United Nations Food and Agricultural Organization and the University of Frankfurt (FAO/UF) [24, 25]. The FAO/UF reported "area equipped for irrigation" (equivalent of GIAM TAAI) as 278 Mha. The differences between the FAO/UF and IWMI GIAM SPIAs (Figure $7 \mathrm{~b}$ and $8 \mathrm{~b}$ ) were significantly smaller than the differences between the FAO/UF and IWMI GIAM FPIAs (Figure 7a and 8a). This was due to inadequate accounting and/or complete absence of informal irrigation (e.g., ground water, small reservoir, tanks) statistics in the national census, uncertainties in IAFs of GIAM, and methodological and definition differences in mapping irrigated areas. Nevertheless, it was obvious that SPIAs (Figure $7 \mathrm{~b}$ and $8 \mathrm{~b}$ ) provide significantly improved estimates of areas when compared with FPIAs (Figure 7a and 8a). 


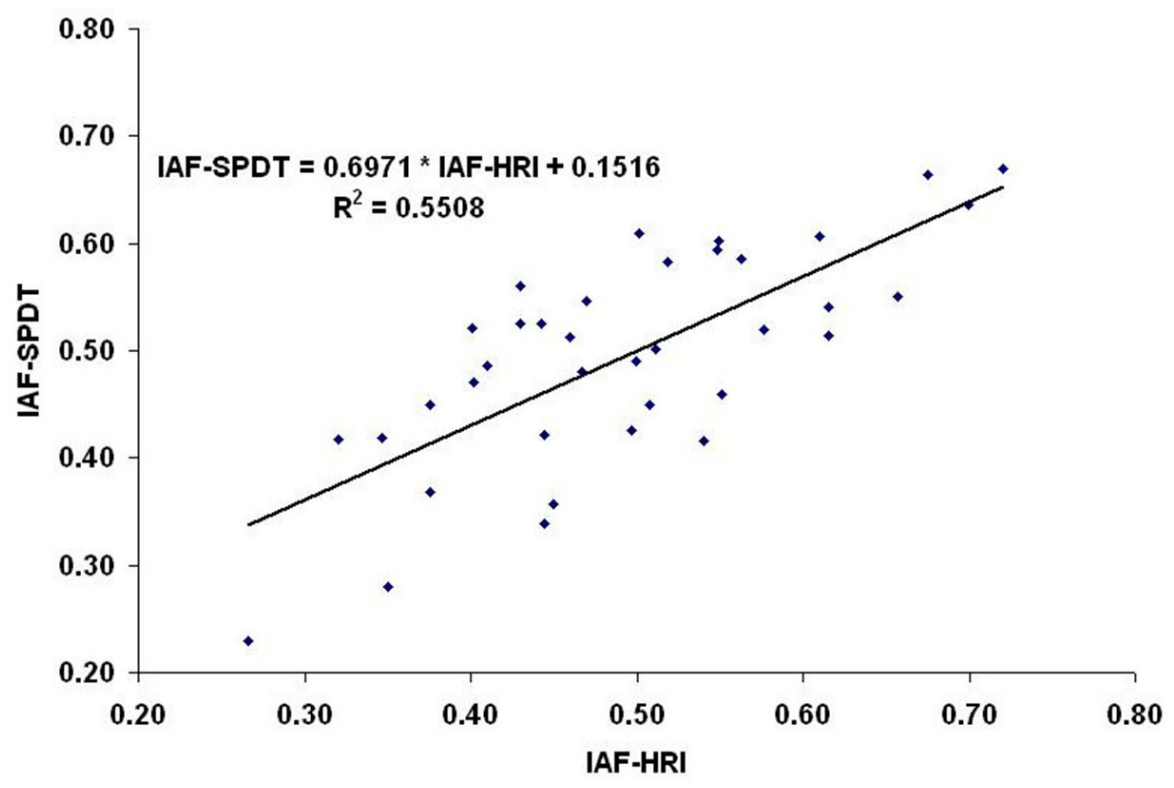

Figure 6. Irrigated area fractions (IAFs) from 2 methods.

The relationship between the IAF-HRI versus IAF-SPDT.

Table 1. Irrigated area fractions (IAFs) using 3 methods. The IAF from: (a) Google Earth Estimates (IAFGEE), high resolution imagery (HRI), and (c) SPDT for the 28 global irrigated area mapping classes.

\begin{tabular}{|c|c|c|c|c|c|c|c|}
\hline \multirow{3}{*}{$\begin{array}{c}\text { Class } \\
\text { Number }\end{array}$} & \multirow[b]{3}{*}{ IAF-GEE } & \multicolumn{2}{|c|}{ Season 1} & \multicolumn{2}{|c|}{ Season 2} & \multicolumn{2}{|c|}{ Continuous } \\
\hline & & \multicolumn{6}{|c|}{ Irrigated Area Fraction - IAF } \\
\hline & & IAF-HRI & IAF-SPDT & IAF-HRI & IAF-SPDT & IAF-HRI & IAF-SPDT \\
\hline 1 & 0.73 & 0.61 & 0.61 & & & & \\
\hline 2 & 0.85 & 0.43 & 0.53 & & & & \\
\hline 3 & 0.68 & 0.40 & 0.52 & & & & \\
\hline 4 & 0.71 & 0.54 & 0.42 & 0.68 & 0.66 & & \\
\hline 5 & 0.63 & 0.62 & 0.51 & 0.62 & 0.54 & & \\
\hline 6 & 0.72 & 0.55 & 0.60 & 0.51 & 0.45 & & \\
\hline 7 & 0.74 & 0.70 & 0.64 & 0.58 & 0.49 & & \\
\hline 8 & 0.64 & 0.38 & 0.37 & 0.32 & 0.42 & & \\
\hline 9 & 0.49 & & & & & 0.41 & 0.49 \\
\hline 10 & 0.61 & & & & & 0.55 & 0.46 \\
\hline 11 & 0.52 & 0.47 & 0.55 & & & & \\
\hline 12 & 0.7 & 0.46 & 0.51 & & & & \\
\hline 13 & 0.68 & 0.27 & 0.22 & & & & \\
\hline 14 & 0.47 & 0.35 & 0.42 & & & & \\
\hline 15 & 0.73 & 0.66 & 0.55 & 0.51 & 0.50 & & \\
\hline 16 & 0.84 & 0.72 & 0.67 & & & & \\
\hline 17 & 0.68 & 0.55 & 0.59 & & & & \\
\hline 18 & 0.73 & 0.38 & 0.45 & & & & \\
\hline 19 & 0.62 & 0.35 & 0.28 & & & & \\
\hline 20 & 0.77 & 0.50 & 0.43 & & & & \\
\hline 21 & 0.77 & 0.56 & 0.59 & & & & \\
\hline 22 & 0.67 & 0.50 & 0.49 & 0.44 & 0.42 & & \\
\hline 23 & 0.69 & 0.44 & 0.34 & 0.45 & 0.36 & & \\
\hline 24 & 0.51 & 0.44 & 0.53 & 0.43 & 0.53 & & \\
\hline 25 & 0.51 & & & & & 0.47 & 0.48 \\
\hline 26 & 0.69 & & & & & 0.40 & 0.47 \\
\hline 27 & 0.76 & & & & & 0.52 & 0.58 \\
\hline 28 & 0.81 & & & & & 0.50 & 0.61 \\
\hline
\end{tabular}

Note: the seasonal IAFwas determined based on crop calendar (Table 1). So when crop does not exist for a season, the IAF is blank. 
Table 2. Cropping calendar to compute areas based on intensity or seasonality of cropping.

\begin{tabular}{|c|c|c|c|c|}
\hline \multirow{2}{*}{$\begin{array}{l}\text { Sl. GMIA } 28 \text { Classes } \\
\text { no. Class Name }\end{array}$} & \multirow{2}{*}{$\begin{array}{l}\text { Single } \\
\text { Crop }\end{array}$} & \multicolumn{2}{|c|}{ Double Crop } & \multirow{2}{*}{$\begin{array}{l}\text { Continuous } \\
\text { Crop } \\
\end{array}$} \\
\hline & & First & Second & \\
\hline 01 Irrigated, surface water, single crop, wheat-corn-cotton & Mar-Nov & & & \\
\hline 02 Irrigated, surface water, single crop, cotton-rice-wheat & Apr-Oct & & & \\
\hline 03 Irrigated, surface water, single crop, mixed-crops & Mar-Oct & & & \\
\hline 04 Irrigated, surface water, double crop, rice-wheat-cotton & & $\begin{array}{l}\text { Mar- } \\
\text { Jun }\end{array}$ & Jun-Oct & \\
\hline 05 Irrigated, surface water, double crop, rice-wheat-cotton-corn & & Jun-Oct & Dec-Mar & \\
\hline 06 Irrigated, surface water, double crop, rice-wheat-plantations & & $\begin{array}{l}\text { Jul-Dec } \\
\text { Jun- }\end{array}$ & Dec-Mar & \\
\hline 07 Irrigated, surface water, double crop, sugarcane & & Dec & Dec-Feb & \\
\hline 08 Irrigated, surface water, double crop, mixed-crops & & Jul-Nov & Dec-Apr & \\
\hline 09 Irrigated, surface water, continuous crop, sugarcane & & & & Jul-May \\
\hline 10 Irrigated, surface water, continuous crop, plantations & & & & Jan-Dec \\
\hline 11 Irrigated, ground water, single crop, rice-sugarcane & Jul-Dec & & & \\
\hline 12 Irrigated, ground water, single crop, corn-soybean & Mar-Oct & & & \\
\hline 13 Irrigated, ground water, single crop,rice and other crops & Mar-Nov & & & \\
\hline 14 Irrigated, ground water, single crop, mixed-crops & Jul-Dec & & & \\
\hline 15 Irrigated, ground water, double crop, rice and other crops & & Jul-Dec & Dec-Mar & \\
\hline 16 Irrigated, conjunctive use, single crop, wheat-corn-soybean-rice & Mar-Nov & & & \\
\hline 17 Irrigated, conjunctive use, single crop, wheat-corn-orchards-rice & Mar-Nov & & & \\
\hline 18 Irrigated, conjunctive use, single crop, corn-soybeans-othercrops & Mar-Oct & & & \\
\hline 19 Irrigated, conjunctive use, single crop, pastures & Mar-Dec & & & \\
\hline 20 Irrigated, conjunctive use, single crop, pasture, wheat, sugarcane & Jul-Feb & & & \\
\hline 21 Irrigated, conjunctive use, single crop, mixed-crops & Mar-Nov & & & \\
\hline 22 Irrigated, conjunctive use, double crop, rice-wheat-sugacane & & Jun-Nov & Dec-Mar & \\
\hline 23 Irrigated, conjunctive use, double crop, sugarcane-other crops & & Apr-Jul & Aug-Feb & \\
\hline 24 Irrigated, conjunctive use, double crop, mixed-crops & & Jul-Dec & Dec-Feb & \\
\hline 25 Irrigated, conjunctive use, continuous crop, rice-wheat & & & & Mar-Feb \\
\hline 26 Irrigated, conjunctive use, continuous crop, rice-wheat-corn & & & & Jun-May \\
\hline 27 Irrigated, conjunctive use, continuous crop, sugacane-orchards-rice & & & & Jun-May \\
\hline 28 Irrigated, conjunctive use, continuous crop, mixed-crops & & & & Jun-May \\
\hline
\end{tabular}


Table 3. Sub-pixel irrigated Areas (SPIAs) computed considering intensity (annualized irrigated areas based on areas of single, double, and continuous crops) and without considering intensity (total area available for irrigation). SPIAs are computed by multiplying irrigated area fractions (IAFs) with full pixel irrigated areas (FPIAs).

\begin{tabular}{|c|c|c|c|c|c|c|c|c|c|c|c|}
\hline $\begin{array}{l}\text { Class } \\
\text { Nr. }\end{array}$ & Class Names & $\begin{array}{l}\text { Full Pixel } \\
\text { area(FPA) }\end{array}$ & $\begin{array}{l}\text { Irrigated } \\
\text { area fraction } \\
\text { based on } \\
\text { IAF-GEE \& } \\
\text { IAF-HRI } \\
\text { (IAF-TAAI) }\end{array}$ & $\begin{array}{l}\text { Total area } \\
\text { available for } \\
\text { irrigation } \\
\text { (TAAI=FPA* } \\
\text { IAF-TAAI) }\end{array}$ & $\begin{array}{l}\text { IAF-season1 } \\
\text { Mean of IAF- } \\
\text { HRI \& IAF- } \\
\text { SPDT }\end{array}$ & $\begin{array}{l}\text { Season } 1 \text { sub } \\
\text { pixel } \\
\text { irrigated } \\
\text { area }(\text { SPA) }= \\
\text { FPA*season1 } \\
\text { IAF }\end{array}$ & $\begin{array}{l}\text { IAF-Season2 } \\
\text { Mean of IAF- } \\
\text { HRI \& IAF- } \\
\text { SPDT }\end{array}$ & $\begin{array}{l}\text { Season } 2 \text { sub } \\
\text { pixel } \\
\text { irrigated } \\
\text { area (SPA) = } \\
\text { FPA*season2 } \\
\text { IAF }\end{array}$ & $\begin{array}{l}\text { IAF- } \\
\text { continuous } \\
\text { season Mean } \\
\text { of IAF-HRI } \\
\text { \& IAF-SPDT }\end{array}$ & $\begin{array}{l}\text { Season } \\
\text { continuous } \\
\text { sub pixel } \\
\text { irrigated } \\
\text { area } \\
\text { (SPA)=FPA* } \\
\text { season } \\
\text { continuous } \\
\text { IAF }\end{array}$ & $\begin{array}{l}\text { Annualized } \\
\text { irrigated } \\
\text { areas } \\
\text { (AIAs)= } \\
\text { season 1 } \\
\text { SPA+ } \\
\text { season2 } \\
\text { SPA+ season } \\
\text { continuous } \\
\text { SPA }\end{array}$ \\
\hline & & hectares & unit less & hectares & unit less & hectares & unit less & hectares & unit less & & hectares \\
\hline 1 & $\begin{array}{l}\text { Irrigated, surface water, single } \\
\text { crop, wheat-corn-cotton } \\
\text { Irrigated, surface water, single }\end{array}$ & $10,639,378$ & 0.73 & $7,766,444$ & 0.61 & $6,471,843$ & & & & & $6,471,843$ \\
\hline 2 & $\begin{array}{l}\text { crop, cotton-rice-wheat } \\
\text { Irrigated, surface water, single }\end{array}$ & $6,896,128$ & 0.85 & $5,880,717$ & 0.55 & $3,813,841$ & & & & & $3,813,841$ \\
\hline 3 & $\begin{array}{l}\text { crop, mixed-crops } \\
\text { Irrigated, surface water, double }\end{array}$ & $14,135,930$ & 0.68 & $9,628,687$ & 0.46 & $6,511,261$ & & & & & $6,511,261$ \\
\hline 4 & $\begin{array}{l}\text { crop, rice-wheat-cotton } \\
\text { Irrigated, surface water, double }\end{array}$ & $69,830,220$ & 0.71 & $49,710,095$ & 0.53 & $36,711,650$ & 0.67 & $46,745,513$ & & & $83,457,163$ \\
\hline 5 & $\begin{array}{l}\text { crop, rice-wheat-cotton-corn } \\
\text { Irrigated, surface water, double }\end{array}$ & $72,501,012$ & 0.63 & $45,369,799$ & 0.56 & $40,938,905$ & 0.52 & $37,483,023$ & & & $78,421,928$ \\
\hline 6 & $\begin{array}{l}\text { crop, rice-wheat-plantations } \\
\text { Irrigated, surface water, double }\end{array}$ & $51,769,022$ & 0.72 & $37,389,472$ & 0.58 & $29,807,112$ & 0.48 & $24,769,631$ & & & $54,576,742$ \\
\hline 7 & $\begin{array}{l}\text { crop, sugarcane } \\
\text { Irrigated, surface water, double }\end{array}$ & $2,569,367$ & 0.74 & $1,910,007$ & 0.67 & $1,716,980$ & 0.53 & $1,372,877$ & & & $3,089,857$ \\
\hline 8 & $\begin{array}{l}\text { crop, mixed-crops } \\
\text { Irrigated, surface water, continuous }\end{array}$ & $60,312,587$ & 0.64 & $38,779,483$ & 0.37 & $22,446,718$ & 0.37 & $22,213,443$ & & & $44,660,161$ \\
\hline 9 & $\begin{array}{l}\text { crop, sugarcane } \\
\text { Irrigated, surface water, continuous }\end{array}$ & 116,418 & 0.49 & 56,932 & & & & & 0.42 & 49,302 & 49,302 \\
\hline 10 & $\begin{array}{l}\text { crop, plantations } \\
\text { Irrigated, ground water, single }\end{array}$ & $13,427,918$ & 0.61 & $8,184,907$ & & & & & 0.44 & $5,865,373$ & $5,865,373$ \\
\hline 11 & $\begin{array}{l}\text { crop, rice-sugarcane } \\
\text { Irrigated, ground water, single }\end{array}$ & $12,780,583$ & 0.52 & $6,653,732$ & 0.49 & $6,255,930$ & & & & & $6,255,930$ \\
\hline 12 & $\begin{array}{l}\text { crop, corn-soybean } \\
\text { Irrigated, ground water, single }\end{array}$ & $5,997,678$ & 0.70 & $4,181,556$ & 0.49 & $2,916,140$ & & & & & $2,916,140$ \\
\hline 13 & $\begin{array}{l}\text { crop, rice and other crops } \\
\text { Irrigated, ground water, single }\end{array}$ & $1,570,188$ & 0.68 & $1,063,691$ & 0.15 & 241,540 & & & & & 241,540 \\
\hline 14 & $\begin{array}{l}\text { crop, mixed-crops } \\
\text { Irrigated, ground water, double }\end{array}$ & $11,799,752$ & 0.47 & $5,590,581$ & 0.38 & $4,518,047$ & & & & & $4,518,047$ \\
\hline 15 & crop, rice and other crops & $3,554,656$ & 0.73 & $2,583,423$ & 0.55 & $1,949,455$ & 0.51 & $1,800,169$ & & & $3,749,623$ \\
\hline 16 & Irrigated, conjunctive use, single & $29,919,283$ & 0.84 & $25,082,625$ & 0.47 & $13,994,126$ & & & & & $13,994,126$ \\
\hline
\end{tabular}


crop, wheat-corn-soybean-rice Irrigated, conjunctive use, single crop, wheat-corn-orchards-rice Irrigated, conjunctive use, single crop, corn-soybeans-other crops

\begin{tabular}{rrrrr}
$10,479,639$ & 0.68 & $7,135,193$ & 0.57 & $5,982,487$ \\
$17,658,270$ & 0.73 & $12,810,184$ & 0.51 & $9,039,700$ \\
$9,150,534$ & 0.62 & $5,672,425$ & 0.25 & $2,287,634$ \\
$2,521,549$ & 0.77 & $1,942,683$ & 0.46 & $1,162,908$ \\
$17,131,259$ & 0.77 & $13,120,827$ & 0.57 & $9,836,226$ \\
$71,510,203$ & 0.67 & $48,004,873$ & 0.49 & $35,361,814$ \\
$1,838,672$ & 0.69 & $1,265,539$ & 0.39 & 720,494 \\
$25,756,897$ & 0.51 & $13,057,718$ & 0.48 & $12,463,458$ \\
$13,969,654$ & 0.51 & $7,186,641$ & & \\
$15,427,976$ & 0.69 & $10,573,933$ & & \\
$13,018,909$ & 0.76 & $9,912,989$ & & \\
$22,304,422$ & 0.81 & $18,011,795$ & & \\
\hline
\end{tabular}

Irrigated, conjunctive use, single

crop, pastures

Irrigated, conjunctive use, single crop, pasture, wheat, sugarcane Irrigated conjunctive use, single Irrigated, conjunctive use, single Irriged, conjunctive

Irrigated, conjunctive use, double

crop, rice-wheat-sugarcane

Irrigated, conjunctive use, double

crop, sugarcane-other crops

Irrigated, conjunctive use, double

Irrigated, conjunctive use,
continuous crop, rice-wheat

Irrigated, conjunctive use,

continuous crop, rice-wheat-corn

Irrigated, conjunctive use,

continuous crop, sugarcane-

orchards-rice

Irrigated, conjunctive use,
continuous crop, mixed-crops

$22,304,422$

$18,011,795$

$588,588,106$

$398,526,951$

$5,982,487$

$9,039,700$

$2,287,634$

$1,162,908$

9,836,226

$66,329,410$

$1,636,766$

$21,164,097$

$0.47 \quad 6,618,040 \quad 6,618,040$

$\begin{array}{lll}0.50 & 7,672,155 & 7,672,155\end{array}$

$\begin{array}{lll}0.55 & 7,168,857 & 7,168,857\end{array}$

$0.56 \quad 12,393,114$

$12,393,114$ 


\subsection{FPIAs and SPIAs at AVHRR 10-km resolution versus National statistics (FAO Aquastat)}

For the purpose 40 leading irrigated area countries that together encompass about $90 \%$ of all global irrigation were considered. The FPIA and SPIAs from the GIAM 10-km were plotted against the $\mathrm{FAO} / \mathrm{UF}$ as shown in the figure $7 \mathrm{a}$ and figure $7 \mathrm{~b}$ respectively. The slope of the 1:1 line improved from a poor 0.36 (Figure $7 \mathrm{a}$ ) to a decent 0.54 (Figure $7 \mathrm{~b}$ ). There was still a considerable difference between the national statistics compiled by FAO/UF and the remote sensing based results of IWMI GIAM. This was mainly as a result of inadequate accounting of informal irrigation (e.g., ground water, small reservoirs, and tanks) in the national irrigated area statistics [8]. The FPIAs provide gross over-estimation of areas [8, 26, 27] requiring SPIAs to determine actual irrigated areas.
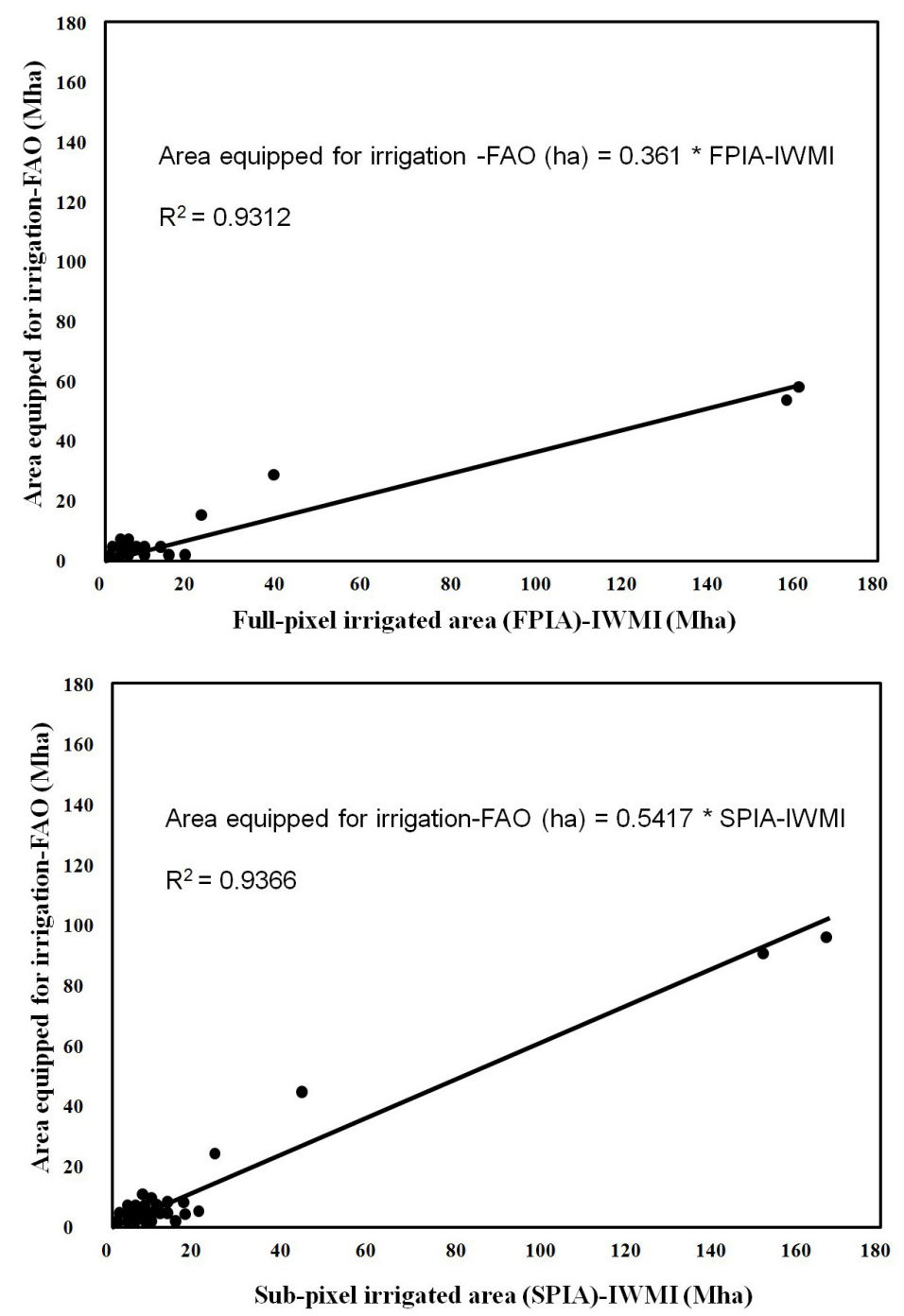

Figure 7. Actual irrigated areas from FAO Aquastat are plotted against FPIA (Figure 7a) and SPIA (Figure $7 b$ ) for 40 leading irrigated area countries which occupy nearly $95 \%$ of all global irrigation. 


\subsection{FPAs and SPAs at MODIS 500-m resolution versus National statistics (FAO Aquastat)}

The census-based national irrigated area statistics from the Ministry of Water Resources (MoWR), Govt. of India [27] were compared with the MODIS 500-m derived FPIAs (Figure 8a) and SPIAs (Figure 7b). The 1:1 line shows that the MoWR statistics was about $75 \%$ of the SPIA (Figure $8 \mathrm{~b}$ ) and only $52 \%$ of FPIA (Figure $8 \mathrm{a}$ ), this clearly indicates the significantly better relationship with SPIA than FPIA. However, still there was a significant gap in areas between the remote sensing based estimates and the national statistics (Figure $8 \mathrm{~b}$ and $7 \mathrm{~b}$ ). The causes for which are described in section 3.0.
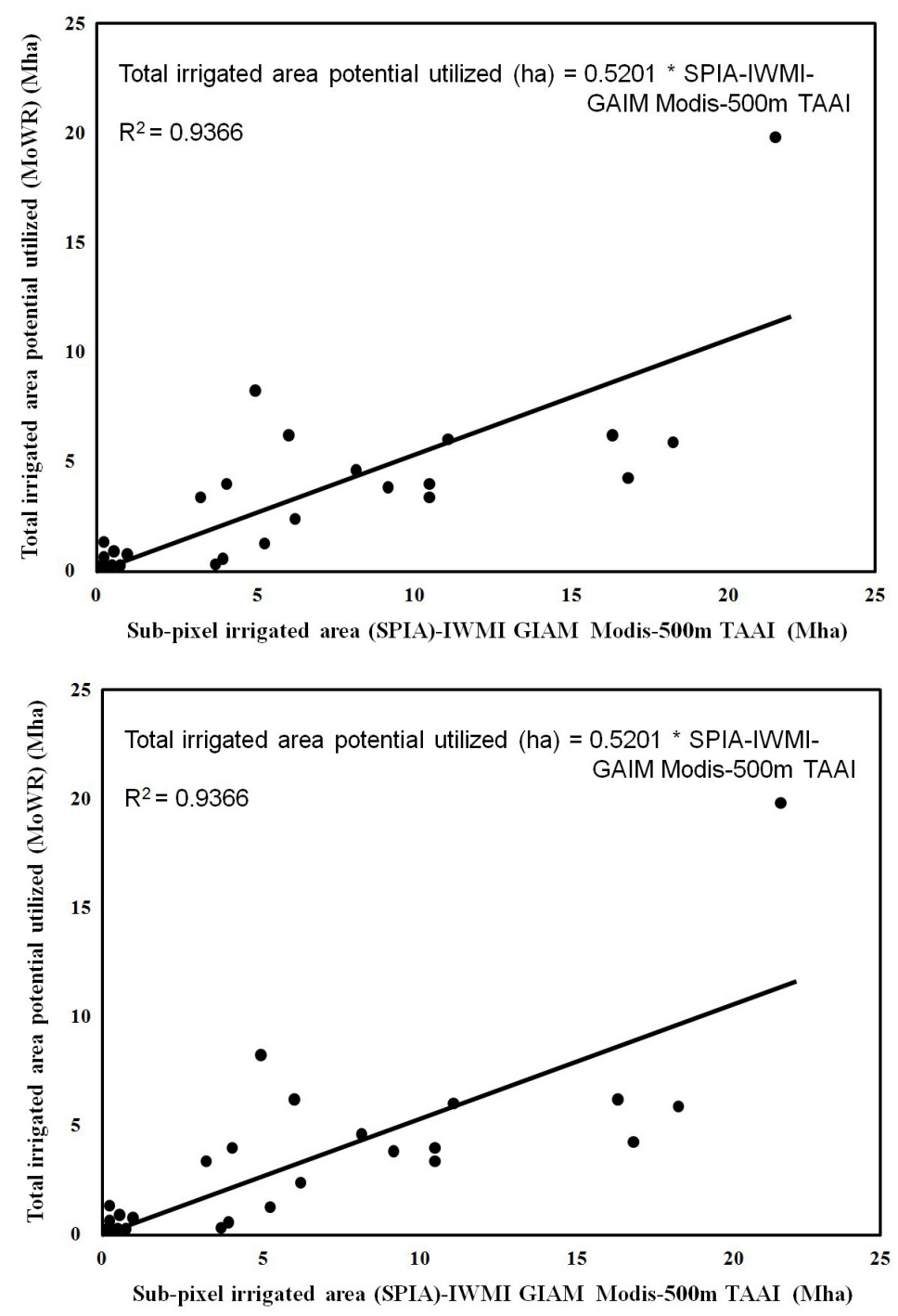

Figure 8. Actual irrigated areas from the Ministry of Water Resources (MoWR) are plotted against FPIA (Figure 8a) and SPIA (Figure 8b) at 500-m resolution for the States in India.

The results also showed an improved relationship between the national statistics with 500-m data (Figure $8 \mathrm{~b}$ and $8 \mathrm{a}$ ) when compared to national statistics and $10-\mathrm{km}$ data (Figure $7 \mathrm{~b}$ and $7 \mathrm{a}$ ). A MODIS 500-m provides an area of 25 hectares per pixel compared to 10,000 hectare per pixel from an 10-kilometer data, an improvement of 400 times. So, it was expected that the MODIS areas were more precise and nearer to the actual areas compared to AVHRR based estimates. 


\subsection{Uncertainties and errors in SPA estimates}

Uncertainties and errors can creep in the SPIA estimates if sufficient care was not taken in IAFGEE, IAF-HRI, and IAF-SPDT estimates. The global SPIA by summing season 1, season 2, and continuous year round cropping when computed by multiplying the FPIA with average of IAF-HRI and IAF-SPDT was 480 Mha (Table 3). The SPIA was: (a) 484 Mha when only IAF-HRI was used, and (b) 476 Mha only when IAF-SPDT was used. The difference in area calculated from the 2 methods was about $8 \mathrm{Mha}$; which accounts to less than $2 \%$ of the total GIAM area. This was a very low margin of error. We did re-visit the fractions for every class that had significant difference between two methods and found that these differences were inevitable as a result of the differences in methods. However, the use of two or more methods help us to compare IAFs obtained from different methods for a class and when there were significant differences in IAFs of different methods, which assist in re-evaluate the fractions for the those class leading to improved IAFs. The resultant IAFs reduced the uncertainties and errors in SPIA estimates. Multiple methods improved the robustness of the IAFs. The IAF from the two methods (Figure 6) provide significant correlation. For IAF-SPDT, further improvement may be possible if we have a better understanding of the percentages for every class in SPDT plot. This will require better groundtruth knowledge of the class in consideration and building relationships between spectral reflectivity and/or NDVI with IAF. Even a small error in IAF estimation can accelerate errors in areas. However, use of 3 methods should provide sufficient robust estimates. Uncertainities can be further reduced if we have greater field knowledge of IAFs in a given area.

The IAF-GEE found to be powerful and easy to use and has the ability to "zoom into" any spot in the world instantaneously. The synoptic view provided by Google makes the IAF-GEE estimates very reliable. The IAF-GEE was ideal to calculate the total area available for irrigation (TAAI) as it assisted in determining the area that was irrigated at the time of estimation as well as area left fallow but equipped for irrigation at the same point of time. There were three significant limitations in IAF-GEE method. First, the absence of very high resolution imagery (VHRI) for every spot in the world. Indeed, for large portions of the world VHRI were absent. Second, the absence of multidate images. Third, the presence of images of varying dates. Third, there is an inherent assumption that the areas "equipped for irrigation" is always not irrigated at particular point of time but will be irrigated at other times. The likelihood that these areas are under permanent fallow has not been fully investigated. IAF-HRI too has the same limitations as second and third points mentioned under IAF-GEE. The IAF-SPDT found to be potentially most powerful method considering the limitation in other toiw methods. Its strength were lies in the: (a) ability to determine areas for every pixel, (b) scale the areas logically in a 2-dimensional brightness-greenness-wetness (BGW) plot, (c) make corrections to areas as we learn more about the class reflectivity and/or NDVI versus percent cover that would aid to assign IAF percentages better in the SPDT plot (Figure 4). 


\section{Conclusions}

The study established the importance and the need for sub-pixel area (SPA) computation for determining actual areas from coarse resolution remote sensing data and espoused practical methods for computing the same. The full pixel areas (FPAs) obtained from coarse-resolution remote sensing data significantly over-estimate areas. Three unique methods of SPA estimation were developed and illustrated by taking a global irrigated area map (GIAM). The sub-pixel irrigated area (SPIA) was computed by multiplying full pixel irrigated area (FPIA) with irrigated area fractions (IAFs). The uncertainties and errors in SPIA computation were directly proportional to errors in irrigated area fractions (IAFs), given that the FPIA remains constant. The three distinct methods of IAFs computations were: (a) Google Earth estimate (IAF-GEE); (b) High resolution imagery (IAF-HRI); and (c) Sub-pixel decomposition technique (IAF-SPDT).

The IAF-HRI and IAF-SPDT fractions were found to be useful in computing SPIAs and account for seasonality or intensity (e.g., first crop, second crop, continuous crop). Thus, they provide net as well gross irrigated areas. The significant correlation was found between IAF-HRI and IAF-SPDT. The overall, the areas from all classes, determined by these 2 methods differed by less than $2 \%$. However, there were individual classes that showed much higher significant differences in areas between 2 methods. Given this fact, using more than one IAF was recommended in order to: (a) reduce uncertainties and errors in areas, and (b) provide more robust estimate of areas. The IAFGEE stands on its own and was useful for computing net irrigated areas without considering intensity or seasonality.

The SPIAs provided significantly better relationships with the national statistics than FPIAs. The FPIAs were also shown gross over-estimate of areas. The paper: (a) highlighted the importance of computing sub-pixel areas for determining accurate areas, and (b) developed and demonstrated 3 unique and practical methods of computing sub-pixel areas.

\section{References and Notes}

1. Xiao, X.; Liu, J.; Zhuang, D.; Frolking, S.; Boles, S.; Xu, B.; Liu, M.; Salas, W.; Moore, B.; $\mathrm{Li}, \mathrm{C}$. Uncertainties in estimates of cropland area in China: a comparison between an AVHRRderived dataset and a Landsat TM-derived dataset. Global and Planetary Change 2003, 37, 297-306.

2. Loveland, T.R.; Reed, B.C.; Brown, J.F.; Ohlen, D.O.; Zhu, J.; Yang, L.; Merchant, J.W. Development of a Global Land Cover Characteristics Database and IGBP DISCover from 1km AVHRR Data. International Journal of Remote Sensing 2000, 21(6-7), 1303-1330.

3. Gallego, F.J. Remote sensing and land cover area estimation. International Journal of Remote Sensing 2004, 25(15), 3019-3047.

4. Foody, G.M.; Lucas, R.M.; Curran, P.J.; Honzak, M. Mapping tropical forest fractional cover from coarse spatial resolution remote sensing imagery. Plant Ecology 1997, 131(2), 143-154.

5. Atkinson, P.M.; Cutler, M.E.J.; Lewis, H. Mapping sub-pixel proportional land cover with AVHRR imagery. International Journal of Remote Sensing 1997, 8(4), 917-935. 
6. Gallego, F.J.; Delince, J.; Rueda, C. Crop area estimates through remote sensing: stability of the regression correction. International Journal of Remote Sensing 1993, 14, 3433-3445.

7. Gonzalez-Alonso, F.; Cuevas, J.M.; Arbiol, R.; Baulies, X. Remote sensing and agricultural statistics: crop area estimation in north-eastern Spain through diachronic Landsat TM and ground sample data. International Journal of Remote Sensing 1997, 18(2), 467-470.

8. Thenkabail, P.S.; Biradar, C.M.; Turral, H.; Noojipady, P.; Li, Y.J.; Vithanage, J.; Dheeravath, V.; Velpuri, M.; Schull, M.; Cai, X.L.; Dutta, R. An Irrigated Area Map of the World (1999) derived from Remote Sensing; Research Report No. 105, International Water Management Institute: Battaramulla, Sri Lanka, 2006; pp. 74.

9. Biggs, T.; Thenkabail, P.S.; Krishna, M.; Gangadhara R.P.; Turral, H. Vegetation phenology and irrigated area mapping using combined MODIS time-series, ground surveys, and agricultural census data in Krishna River Basin, India. International Journal of Remote Sensing 2006, 27(19), 4245-4266.

10. Fang, H.; Wu, B.; Liu, H.; Huang, X. Using NOAA AVHRR and Landsat TM to estimate rice area year by year. International Journal of Remote Sensing 1998, 19(3), 521-525.

11. Xiao, X.; Boles, S.; Frolking, S.; Salas, W.; Moore, B.; Li, C.; He, L.; Zhao, R. Landscapescale characterization of cropland in China using VEGETATION sensor data and Landsat TM imagery. International Journal of Remote Sensing 2002, 23, 3579- 3594.

12. DeFries, R.; Hansen, M.; Steininger, M.; Dubayah, R.; Sohlberg, R.; Townshend, J. Subpixel forest cover in Central Africa from Multisensor, multitemporal data. Remote Sensing of Environment 1997, 60, 226-246.

13. Quarmby, N.A. Towards continental scale crop area estimation. International Journal of Remote Sensing 1992, 13(5), 981-989.

14. Ozdogan, M.; Woodcock, C.E. Resolution dependent errors in remote sensing of cultivated areas. Remote Sensing of Environement 2006, 103(2), 203-217.

15. Thenkabail, P.S.; Schull, M.; Turral, H. Ganges and Indus river basin Land Use/Land Cover (LULC) and irrigated area mapping using continuous streams of MODIS data. Remote Sensing of Environment 2005, 95(3), 317-341.

16. Thenkabail, P.S.; Gangadhara, R.P.; Biggs, T.; Krishna, M.; Turral, H. Spectral Matching Techniques to Determine Historical Land use/Land cover (LULC) and Irrigated Areas using Time-series AVHRR Pathfinder Datasets in the Krishna River Basin, India. Photogrammetric Engineering and Remote Sensing 2007, 73(9), 1029-1040.

17. Settle, J.J.; Drake, N.A. Linear mixing and the estimation of ground cover proportions. International Journal of Remote Sensing 1993, 14, 1159-1177.

18. Drake, N.A.; Mackin, S.; Settle, J.J. Spectral matching and mixture modelling of SWIR AVIRIS imagery. In Proceedings of the 23rd Annual Conference of the Remote Sensing Society: RSS'97 Observations \& Interactions, Reading, Sept 2-4, 1997; pp. 410-415.

19. Purevdorj, T.; Tateishi, R.; Ishiyama, T.; Honda, Y. Relationships between percent vegetation cover and vegetation indices. International Journal of Remote Sensing 1998, 19(18), 35193535 .

20. Purevdorj, T.; Tateishi, D. Estimation of percent vegetation cover of grassland in Mongolia using NOAA AVHRR data. Poster presentation, ACRS 1997; GIS Development.net. 
21. Barnes, E.M.; Clarke, T.R.; Richards, S.E. In Proceedings of the Fifth International Conference on Precision Agriculture, Bloomington, Minnesota, Jul 16-19, 2000; Robert, P.C., Rust, R.H., Larson, W.E., Eds.; Precision Ag Center: St. Paul, MN, 2001.

22. Hallant, L.H.J.; Ian, P.P.; Chris, M.; Priestley, G. Prediction of sheet and rill erosion over the Australian Continent, Incorporating monthly soil loss distribution. Technical Report 13/01 for CSIRO Land and Water: Canberra, Australia, 2001.

23. Li, X.B.; Chen, Y.H.; Shi, P.J.; Chen, J. Detecting Vegetation Fractional Coverage of Typical Steppe in Northern China Based on Multi-scale Remotely Sensed Data. Acta Botanica Sinica 2003, 45(10), 1146-1156.

24. Siebert, S.; Döll, P.; Hoogeveen, J.; Faurès, J-M.; Frenken, K.; Feick, S. Development and validation of the global map of irrigation areas. Hydrology and Earth System Sciences 2005, 9 , 535-547.

25. Siebert, S.; Hoogeveen, J.; Frenken, K. Irrigation in Africa, Europe and Latin America Update of the digital global map of irrigation areas to version 4. Frankfurt Hydrology Paper 05; Institute of Physical Geography: Rome, Italy and University of Frankfurt: Frankfurt am Main, Germany and Food and Agriculture Organization of the United Nations: Rome, Italy, 2006.

26. Liu, J.B. Study of spatial-temporal feature of modern land-use change in China: using remote sensing techniques. Quaternary Sciences 2000, 20(2), 229-239.

27. 3rd Census of Minor Irrigation Schemes (2000-01); Ministry of Water Resources, Govt. of India: New Delhi, India, 2005.

(C) 2007 by MDPI (http://www.mdpi.org). Reproduction is permitted for noncommercial purposes. 